\title{
Epidemiology and Comorbidity in Children with Psoriasis and Atopic Eczema
}

\author{
Matthias Augustin ${ }^{a}$ Marc A. Radtke ${ }^{a}$ Gerd Glaeske ${ }^{c}$ Kristian Reich ${ }^{b}$ \\ Enno Christophers ${ }^{d}$ Ines Schaefer ${ }^{a}$ Arnd Jacobi $^{\mathrm{a}}$ \\ anstitute for Health Services Research in Dermatology and Nursing (IVDP), University Medical Centre \\ Hamburg-Eppendorf (UKE) and bermatologikum Hamburg, Hamburg, 'Centre for Social Policy Research, \\ University of Bremen, Bremen, and d Department of Dermatology, University of Kiel, Kiel, Germany
}

\section{Key Words}

Atopic eczema · Children · Comorbidity - Epidemiology · Health care $\cdot$ Psoriasis

\begin{abstract}
Background: First studies have shown that juvenile psoriasis is associated with an increased prevalence of comorbidity. Objectives: We carried out a data analysis to characterise the profiles of comorbidity in children with psoriasis and atopic eczema. Methods: Prevalence data were derived from the database of a German statutory health insurance company according to ICD-10 codes $L 40$ (psoriasis) and L20 (atopic eczema) of children up to 18 years insured in 2009. Results: Data sets included 1.64 million persons and 293,181 children. 1,313 children $=0.45 \%(0.42-0.47)$ had a diagnosis of psoriasis and $30,354=10.35 \%(10.24-10.47)$ had a diagnosis of atopic eczema. Obesity, hyperlipidaemia, arterial hypertension and diabetes were more often diagnosed in children with psoriasis in comparison to all children without psoriasis and to those with atopic eczema. Conclusion: Children with psoriasis and atopic eczema show different and specific patterns of comorbidity which should be detected early and treated adequately.
\end{abstract}

(c) 2015 S. Karger AG, Basel
(C) 2015 S. Karger AG, Base

$1018-8665 / 15 / 2311-0035 \$ 39.50 / 0$

\section{Introduction}

Psoriasis vulgaris is a common chronic inflammatory disease in both children and adults which leads to a severe burden concerning quality of life $[1,2]$. Recent studies have demonstrated two patient cohorts, one with earlyonset (type I) and the other with late-onset (type II) psoriasis $[3,4]$. In addition, psoriasis in childhood revealed a median age of onset between 7 and 10 years [5-8]. Juvenile psoriasis differs from psoriasis beginning in adulthood and is characterised by an increased rate of guttate psoriasis following infections, particularly with streptococci, or psychosocial stress situations [9]. Interestingly, only approximately $30-60 \%$ of children with juvenile psoriasis develop plaque-type psoriasis [9], predominantly affecting the scalp, face and intertriginous areas. Like in adults, nail psoriasis is a common feature [10]. Data from a German statutory health insurance organization revealed a single-year prevalence of $0.71 \%$ in juvenile psoriasis [11]. Further analysis of juvenile psoriasis showed a prevalence in the UK of about $0.6 \%$ in children $0-9$ years old and of $1.4 \%$ in children from 10 to 19 years [12].

Atopic eczema represents a chronic inflammatory skin disorder with a burdensome disease pathology. It is characterised by pathognomonic eczematous skin lesions,

\section{KARGER 125}

E-Mail karger@karger.com www.karger.com/drm
Dr. med. Arnd Jacobi, MA

Institute for Health Services Research in Dermatology and Nursing (IVDP) University Medical Centre Hamburg-Eppendorf (UKE)

Martinistr. 52, DE-20246 Hamburg (Germany)

E-Mail a.jacobi@uke.de 
typically with a flexural distribution, and often affects children's faces. Atopic eczema is associated with psychosocial stress and a family history of allergies [13-15]. In general atopic eczema starts in early childhood and features clinical symptoms including pruritus and skin dryness. In children prevalence rates between 7.4 and $37 \%$ have been observed [16]. In adults atopic eczema has been reported more rarely; in Germany the prevalence rate in a recent study was $1.3 \%$ [17].

Comorbidity is an important feature both of psoriasis and atopic eczema in adults [18-21]. In contrast, epidemiologic data on children are rare. In a previous study it was shown that patients with juvenile psoriasis also show increased rates of cardiovascular disease and metabolic syndrome [11], whereas children with atopic eczema show a strong association with other atopic diseases, especially allergic rhinitis and bronchial asthma [22, 23]. However, in these analyses it was unclear whether there is a reporting bias due to more frequent physician visits among those patients. In order to control for such bias and to obtain further insight in the pattern of comorbidity, the study reported below was performed. Moreover our study provides the first comparative data of prevalence and comorbidity both in psoriasis and in atopic eczema.

\section{Methods}

Prevalence data were derived from the database of a German statutory health insurance company (Gmünder Ersatzkasse) according to ICD-10 codes L40 (PSO) for psoriasis and L20 (AE) for atopic eczema. Data extraction involved all data sets of persons younger than 18 insured in 2009. In addition, prevalence rates of comorbidity were evaluated by ICD-10 diagnoses. These included among others allergic rhinitis, arterial hypertension, arthritis, bronchial asthma, diabetes mellitus, hyperlipidaemia, ischaemic heart disease, obesity, metabolic syndrome, ulcerative colitis and vitiligo.

\section{Statistics}

Descriptive data analyses were conducted and calculated with the statistical program SAS by the Centre for Social Policy Research, University of Bremen, Bremen, Germany. For comorbidity, prevalence ratios were performed by comparing the prevalence rate of children in the psoriatic and atopic eczema group to the respective rate in the non-psoriatic and non-atopic eczema groups. Prevalences are given as percentage values. For comparison of comorbidities, prevalence ratios were calculated by relating the prevalence rate of children in the psoriatic group and the atopic dermatitis group with the respective rate in the non-psoriatic and non-atopic dermatitis group. Their corresponding 95\% confidence intervals were computed by a general method based on constant $\chi^{2}$ boundaries. Differences with a probability of a type I ( $\alpha$ ) error of $\leq 0.05$ were considered statistically significant.

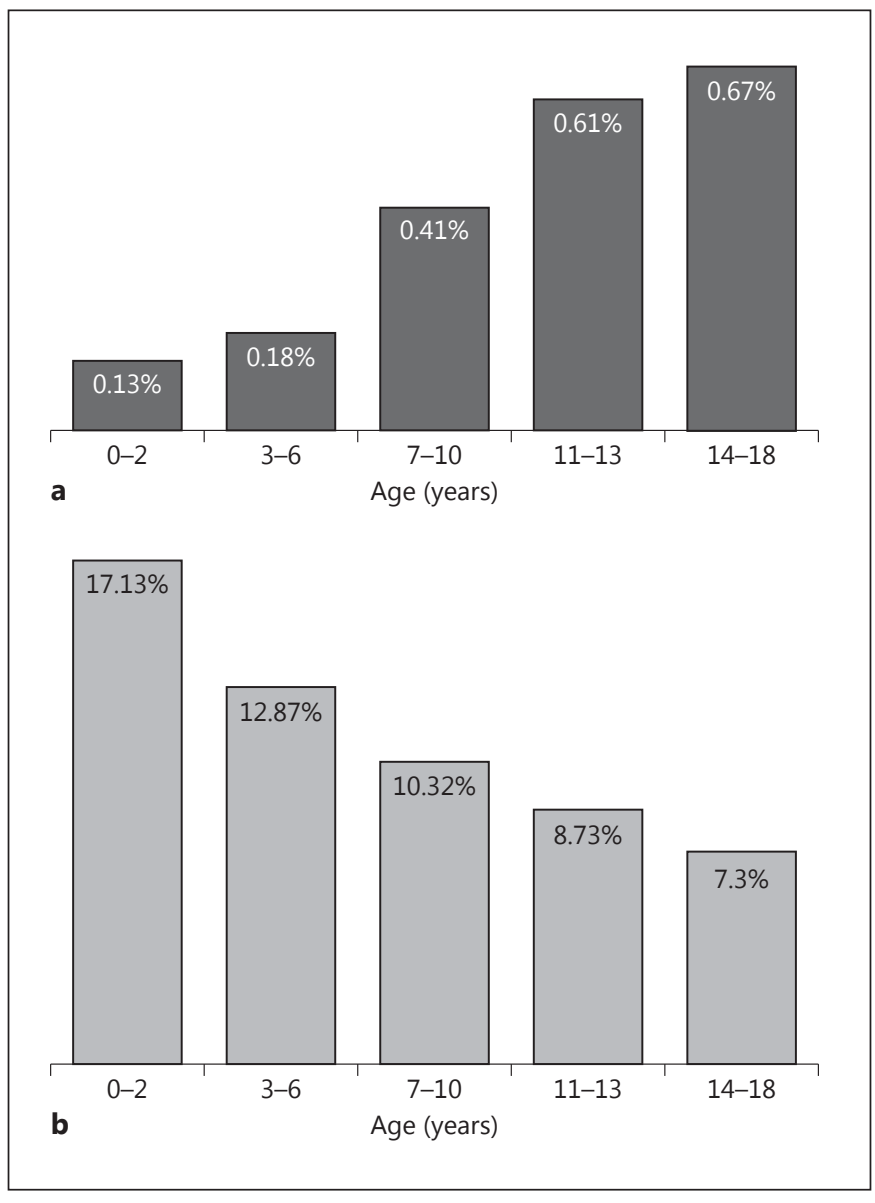

Fig. 1. Prevalence of psoriasis (a) and atopic eczema (b) in children according to age groups.

\section{Results}

The data set comprised 1.64 million persons nationwide, including 293,181 children and young adults up to 18 years $(150,244$ boys, 142,937 girls $) .1,313$ children $=$ $0.45 \%(0.42-0.47)$ carried the diagnosis of psoriasis and $30,354=10.35 \%(10.24-10.47)$ that of atopic eczema (fig. 1). The data demonstrate that the psoriasis prevalence in children correlates in a linear manner with age, whereas the prevalence of atopic eczema shows an early peak in the ages between 1 and 6 years and a consecutive lower rate. The prevalence of juvenile psoriasis increased from $0.13 \%(0.10-0.18)$ at the age of $0-2$ years to $0.67 \%$ $(0.62-0.73)$ at the age of $14-18$ years. In contrast, the prevalence of children with atopic eczema decreased from $17.13 \%(16.65-17.62)$ at the age of $0-2$ years to $7.3 \%$ (7.11-7.49) at the age of $14-18$ years (fig. 1).
Augustin/Radtke/Glaeske/Reich/ Christophers/Schaefer/Jacobi 
Table 1. Prevalence (\%) and prevalence ratios of selected comorbidities in children with psoriasis $(\mathrm{n}=1,313)$ and without psoriasis $(\mathrm{n}=291,868)$ and in children with atopic eczema $(\mathrm{n}=30,354)$ and without atopic eczema $(\mathrm{n}=262,827)$

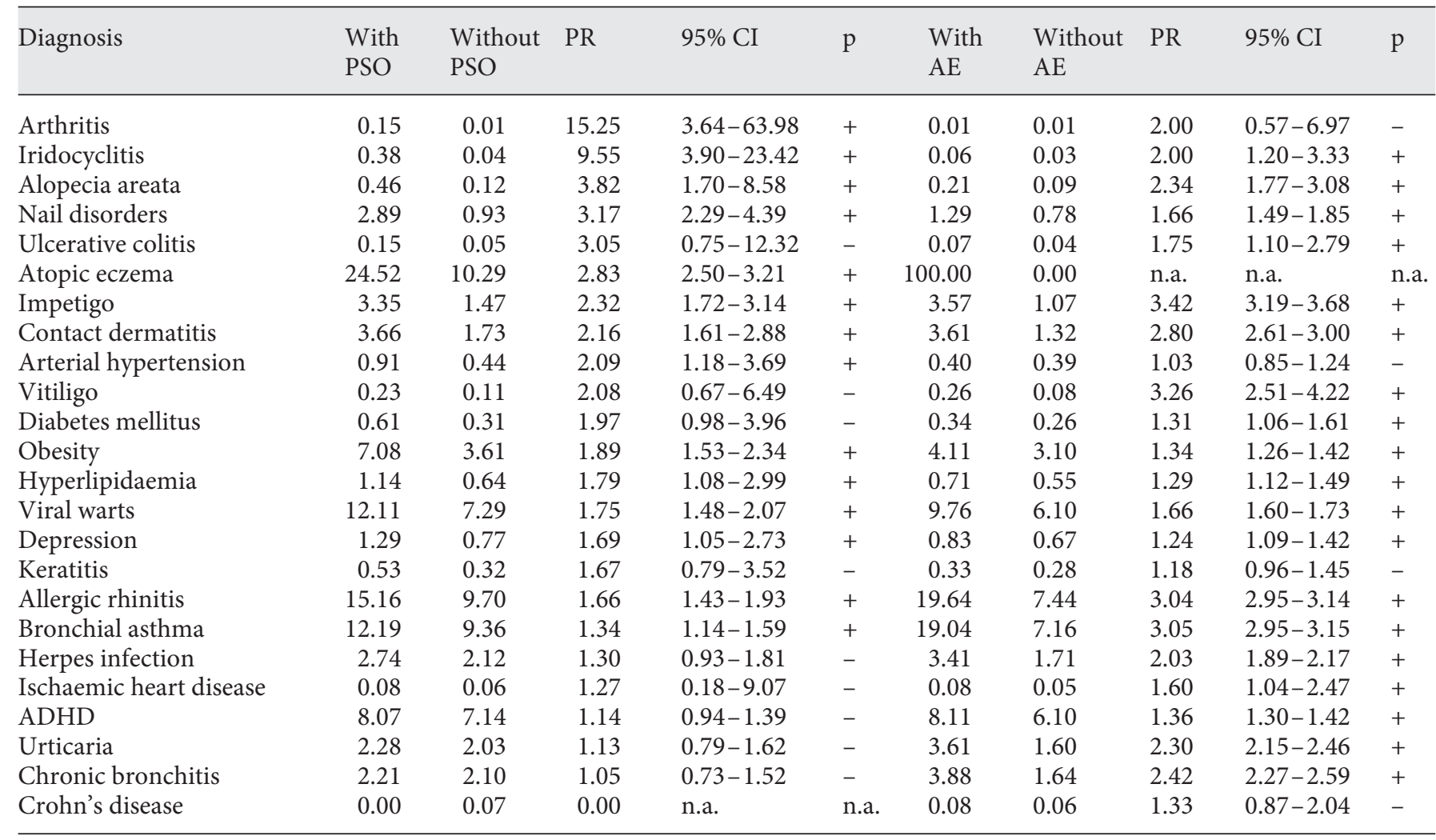

$\mathrm{ADHD}=$ Attention deficit hyperactivity disorder; $\mathrm{AE}=$ atopic eczema; $\mathrm{CI}=$ confidence interval; $\mathrm{n} . \mathrm{a} .=$ not applicable; $\mathrm{PR}=$ prevalence ratio; $\mathrm{PSO}=$ psoriasis; $+=$ statistically significant $(\mathrm{p}<0.05)$.

The most frequent comorbidity in psoriasis was allergic rhinitis (15.16\%), bronchial asthma (12.19\%) and obesity (7.08\%) (table 1). In addition obesity, hyperlipidaemia, arterial hypertension and diabetes were more often diagnosed in patients with psoriasis compared to the control groups of children without psoriasis and patients with atopic eczema, respectively. Thus the prevalence rate of obesity was significantly elevated among young patients with psoriasis $(7.08 \%)$ compared to children without psoriasis $(3.61 \%)$ and patients with atopic eczema $(4.11 \%)$. The prevalence rates of hyperlipidaemia (1.14\%), arterial hypertension (0.91\%) and diabetes mellitus $(0.61 \%)$ were elevated in comparison to all children without psoriasis $(0.64 \%, 0.44 \%, 0.31 \%)$ and to those with atopic dermatitis $(0.71 \%, 0.40 \%, 0.34 \%)$. Furthermore high relative risks were found especially in psoriasis for arthritis and iridocyclitis. Thus arthritis and iridocyclitis were seen 15.3 and 9.6 times as often in psoriatic patients as in children without psoriasis, respectively (table 1).

In atopic eczema the most frequent comorbidity observed was allergic rhinitis (19.64\%), followed by bronchial asthma (19.04\%) (table 1). High relative risks were found in atopic eczema for impetigo and vitiligo. Thus impetigo and vitiligo were seen 3.4 and 3.3 times as often in patients with atopic eczema as in children without this atopic disease. Furthermore bronchial asthma and allergic rhinitis were seen 3.1 and 3.0 times as often in atopic dermatitis patients as in children without this disease, respectively.

Although both diseases, psoriasis and atopic eczema, may share some allergic disorders, we observed significant differences between patients with psoriasis or atopic eczema and children without these diseases regarding the prevalence of comorbidities (table 1). 


\section{Discussion}

This data analysis was conducted in order to obtain further insight into the prevalence and the comorbidity patterns of patients with juvenile psoriasis and atopic eczema. The data set of patients from the German statutory health insurance Gmünder Ersatzkasse has been shown to be robust and valid for epidemiologic research [24]. The prevalence data in children between 0 and 18 years of $0.45 \%$ for psoriasis and $10.35 \%$ for atopic eczema are within the same range as published in earlier studies. The results confirm previous data on the dimension of psoriasis prevalence in childhood and adolescence [11]. Although there is a difference in prevalence of $0.7 \%$ as previously described [11] versus $0.45 \%$ in this study, the dimension of psoriasis in children remains significant. Our prevalence data confirm results of a study in the UK [12]. In that study, within the first 10 years the prevalence of psoriasis in the UK was $0.55 \%$ and thus similar to our data $(0.45 \%)$. Also the prevalence in juvenile psoriasis increases constantly from early childhood up to the age of 18 years (fig. 1), whereas the prevalence in children with atopic dermatitis decreases over the years, underlining fundamental differences between these two common disorders.

The present study was conducted in order to further analyse comorbidities in patients with psoriasis and atopic dermatitis. It is remarkable that there are specific comorbidity patterns in this large data set from the health insurance companies, which confirms clinical findings from other epidemiologic studies in children with psoriasis and atopic eczema $[11,20]$. Specifically, clusters of comorbidities that are known to be associated with adult psoriasis [25-32] are also seen in juvenile psoriasis. In contrast to atopic dermatitis, children with psoriasis are characterised by a significantly elevated prevalence of obesity, hyperlipidaemia, arterial hypertension, diabetes and other forms of the metabolic syndrome.

In light of these observations, it has been reported that patients with psoriasis may show signs of insulin resistance and are at risk of developing metabolic disorders, hypothetically labelled the 'psoriatic march' [19]. The present data indicate that metabolic disorders may already occur in juvenile psoriasis, and screening and interdisciplinary management are advised.

Atopic eczema in children is of high prevalence and characterised by concomitant atopic diseases, in particular allergic rhinitis and bronchial asthma. Interestingly, when compared to healthy children, these comorbid- ities are noted to be mildly but significantly elevated also in psoriasis. There seems to be a subgroup of children who - within the limitations of health insurance data - are even affected by both psoriasis and atopic eczema $(24.5 \%$ of children with psoriasis also are affected by atopic eczema). Furthermore, impetigo and vitiligo were seen 3.4 and 3.3 times as often in children with atopic eczema. It is well known that disorders such as impetigo contagiosa and vitiligo are more often associated with atopic dermatitis $[4,20]$. Our results give support to these findings.

The coding of medical entities with the ICD-10 classification in Germany is used for reimbursement, and the reliability and disease severity of diagnosis coding is still not clear [33]. However, with regard to the evaluation of population-based studies in Germany, ICD-10 coding often is the only available information. Thus limitations in the study, which appear in the analysis of health insurance data, cannot be completely ruled out. This includes the option of incorrect diagnoses, since these were not verified by the authors. Moreover the prevalence rates can only be attributed to those patients seeking medical care. It may be possible that children with psoriasis and atopic eczema fail to seek medical care. However, this rate probably is low, since there is a high burden of disease to the children and their families in both disorders and there is no financial burden from physician visits to the children and their families in Germany $[11,20]$. Moreover, studies on psoriasis care and self-medication in Germany by pharmacies have shown that very few patients buying medication and doing selfmedication in Germany do not refer to a prescription. Furthermore most Germans are insured, since health care provision is based on a statutory health insurance system [34]. Until now, only few validation studies for routine data of German statutory health insurances exist, and the true underlying number of children with each ICD-10 diagnosis can only be estimated. However, a current study focused on the validity of the coded diagnosis of the used data set with regard to the coding of general practitioners in Berlin [35]. In that trial the authors reported a correctness of musculoskeletal disorder coding of $61 \%$ and of M54 coding for dorsalgia of $71 \%$ [35].

Our data confirm known differences in the comorbidity spectrum seen in psoriasis and atopic eczema in adults. As shown here, children with psoriasis show increased comorbidity associated with obesity. In contrast, atopic eczema in children is associated with significantly increased rates of atopic comorbidity such as allergic rhini-
38

Dermatology 2015;231:35-40 DOI: $10.1159 / 000381913$
Augustin/Radtke/Glaeske/Reich/ Christophers/Schaefer/Jacobi 
tis and bronchial asthma. These specific patterns and the differences between children with psoriasis and with atopic eczema indicate that there is no overreporting bias in this study due to just an increased rate of physician visits. In total, it can be assumed that the basic outcomes of the study both on the disease prevalence and the prevalence of comorbidity are valid for the German population. The data support the importance of the German national health care goals, which demand early detection and treatment of psoriasis and its comorbidity in children. The same claim must also be set for children with atopic eczema.

\section{Acknowledgment}

This study was supported by research grants from Biogen Idec $\mathrm{GmbH}$, Ismaning, Germany.

\section{Disclosure Statement}

M. Augustin, A. Jacobi, M. A. Radtke and K. Reich received funding from Biogen Idec for research and were invited speakers and consultants for this company. E. Christophers received funding from Biogen Idec for consulting and oral presentations. G. Glaeske and I. Schaefer have no conflicts of interest to declare.

\section{References}

$>_{1}$ Gudjonsson JE, Elder JT: Psoriasis: epidemi- $>12$ Gelfand JM, Weinstein R, Porter SB, Neiology. Clin Dermatol 2007;25:535-546.

2 Augustin M, Krüger K, Radtke MA, Schwippl I, Reich K: Disease severity, quality of life and health care in plaque-type psoriasis: a multicenter cross-sectional study in Germany. Dermatology 2008;216:366-372.

3 Altobelli E, Petrocelli R, Marziliano C, Fargnoli MC, Maccarone M, Chimenti S, Peris K: Family history of psoriasis and age at disease onset in Italian patients with psoriasis. $\mathrm{Br} \mathrm{J}$ Dermatol 2007;156:1400-1401.

4 Henseler T, Christophers E: Disease concomitance in psoriasis. J Am Acad Dermatol 1995; 32:982-986.

5 Fan X, Xiao FL, Yang S, Liu JB, Yan KL, Liang $\mathrm{YH}$, Sun LD, Du WH, Jin YT, Zhang XJ: Childhood psoriasis: a study of 277 patients from China. J Eur Acad Dermatol Venereol 2007;21:762-765.

-6 Seyhan M, Coşkun BK, Sağlam H, Ozcan H, Karincaoğlu Y: Psoriasis in childhood and adolescence: evaluation of demographic and clinical features. Pediatr Int 2006;48:525-530.

7 Kumar B, Jain R, Sandhu K, Kaur I, Handa S: Epidemiology of childhood psoriasis: a study of 419 patients from northern India. Int J Dermatol 2004;43:654-658.

8 Nanda A, Kaur S, Kaur I, Kumar B: Childhood psoriasis: an epidemiologic survey of 112 patients. Pediatr Dermatol 1990;7:19-21.

-9 Raychaudhuri SP, Gross J: A comparative study of pediatric onset psoriasis with adult onset psoriasis. Pediatr Dermatol 2000;17: 174-178.

10 Al-Mutairi N, Manchanda Y, Nour-Eldin O: Nail changes in childhood psoriasis: a study from Kuwait. Pediatr Dermatol 2007;24:7-10.

11 Augustin M, Glaeske G, Radtke MA, Christophers E, Reich K, Schäfer I: Epidemiology and comorbidity of psoriasis in children. Br J Dermatol 2010;162:633-636. mann AL, Berlin JA, Margolis DJ: Prevalence and treatment of psoriasis in the United Kingdom: a population-based study. Arch Dermatol 2005; 141:1537-1541.

13 Leung DYM: New insights into atopic dermatitis: role of skin barrier and immune dysregulation. Allergol Int 2013;62:151-161.

14 Proudfoot LE, Powell AM, Ayis S, Barbarot S, Baselga Torres E, Deleuran M, Fölster-Holst R, Gelmetti C, Hernández-Martin A, Middelkamp-Hup MA, Oranje AP, Logan K, Perkin M, Patrizi A, Rovatti G, Schofield O, Spuls P, Svensson Å, Vestergaard C, Wahlgren CF, Schmitt J, Flohr C; European Dermato-Epidemiology Network (EDEN): The European TREatment of severe Atopic eczema in children Taskforce (TREAT) survey. Br J Dermatol 2013;169:901-909.

15 Guttman-Yassky E, Nograles K, Krueger J: Contrasting pathogenesis of atopic dermatitis and psoriasis - part I: clinical and pathologic concepts. J Allergy Clin Immunol 2011;127: 1110-1118.

16 Beikert FC, Langenbruch AK, Radtke MA, Kornek T, Purwins S, Augustin M: Willingness to pay and quality of life in patients with atopic dermatitis. Arch Dermatol Res 2013; 306:279-286.

$>17$ Augustin M, Herberger K, Hintzen S, Heigel H, Franzke N, Schäfer I: Prevalence of skin lesions and need for treatment in a cohort of 90880 workers. Br J Dermatol 2011;165:865873.

18 Gelfand JM, Troxel AB, Lewis JD, Kurd SK, Shin DB, Wang X, Margolis DJ, Strom BL: The risk of mortality in patients with psoriasis: results from a population-based study. Arch Dermatol 2007;143:1493-1499.
19 Boehncke WH, Boehncke S, Tobin AM, Kirby B: The 'psoriatic march': a concept of how severe psoriasis may drive cardiovascular comorbidity. Exp Dermatol 2011;20:303-307.

20 Silverberg JI, Simpson EL: Association between severe eczema in children and multiple comorbid conditions and increased healthcare utilization. Pediatr Allergy Immunol 2013;24:476-486.

21 Spergel JM: From atopic dermatitis to asthma: the atopic march. Ann Allergy Asthma Immunol 2010;105:99-106; quiz 107-109, 117.

22 Akdis CA, Akdis M, Bieber T, Bindslev-Jensen C, Boguniewicz M, Eigenmann P, Hamid Q, Kapp A, Leung DY, Lipozencic J, Luger TA, Muraro A, Novak N, Platts-Mills TA, Rosenwasser L, Scheynius A, Simons FE, Spergel J, Turjanmaa K, Wahn U, Weidinger S, Werfel T, Zuberbier T; European Academy of Allergology; Clinical Immunology/American Academy of Allergy, Asthma and Immunology/PRACTALL Consensus Group: Diagnosis and treatment of atopic dermatitis in children and adults: European Academy of Allergology and Clinical Immunology/American Academy of Allergy, Asthma and Immunology/PRACTALL Consensus Report. Allergy 2006;61:969-987.

23 Akdis CA: Allergy and hypersensitivity: mechanisms of allergic disease. Curr Opin Immunol 2006;18:718-726.

24 Augustin M, Reich K, Glaeske G, Schaefer I, Radtke MA: Co-morbidity and age-related prevalence of psoriasis: analysis of health insurance data in Germany. Acta Derm Venereol 2010;90:147-151.

25 Christophers E: Comorbidities in psoriasis. Clin Dermatol 2007;25:529-534.

26 Pearce DJ, Morrison AE, Higgins KB, Crane MM, Balkrishnan R, Fleischer AB Jr, Feldman SR: The comorbid state of psoriasis patients in a university dermatology practice. J Dermato$\log$ Treat 2005;16:319-323. 
27 Mrowietz U, Elder JT, Barker J: The importance of disease associations and concomitant therapy for the long-term management of psoriasis patients. Arch Dermatol Res 2006; 298:309-319.

28 Sterry W, Strober BE, Menter A; International Psoriasis Council: Obesity in psoriasis: the metabolic, clinical and therapeutic implications. Report of an interdisciplinary conference and review. Br J Dermatol 2007;157: 649-655.

29 Gottlieb AB, Chun C, Dann F: Psoriasis comorbidities. J Dermatolog Treat 2008;19:521.
30 Boehncke S, Thaci D, Beschmann H, Ludwig RJ, Ackermann H, Badenhoop K, Boehncke WH: Psoriasis patients show signs of insulin resistance. Br J Dermatol 2007;157:12491251.

31 Schön MP, Boehncke WH: Psoriasis - immunopathogenesis, genetics and therapeutic perspectives. N Engl J Med 2005;352:1899_ 1912.

32 Jacobi A, Kupke C, Behzad M, Hertl M: Comorbidities, metabolic risk profile and healthrelated quality of life in German patients with plaque-type psoriasis: a cross-sectional prospective study. Int J Dermatol 2013;52:10811087.
33 Ochsmann EB, Escobar Pinzón CL, Letzel S, Kraus T, Michaelis M, Muenster E: Prevalence of diagnosis and direct treatment costs of back disorders in 644,773 children and youths in Germany. BMC Musculoskelet Disord 2010;11:193.

34 Franzke N, Montenbruck M, Langenbruch AK, Beikert FC, Kresken J, Augustin M: Drug supply for psoriasis - results from a national pharmacy network. J Dtsch Dermatol Ges 2013;11:638-643.

35 Erler A, Beyer M, Muth C, Gerlach FM, Brennecke R: Garbage in - garbage out? Validity of coded diagnoses from GP claims records. Gesundheitswesen 2009;71:823-831. 